\title{
A perspectiva social de moradores atingidos pela Hidrelétrica Baixo Iguaçu/PR
}

Francine Herpich

Universidade Tecnológica Federal do Paraná

Norma Kiyota

Instituto Agronômico do Paraná - IAPAR

Recebido: 25/05/2017 Versão revisada (entregue): 26/03/2018 Aprovado: 27/03/2018

\section{Resumo}

Este artigo resulta de estudo que procurou compreender a perspectiva social dos moradores atingidos pela Usina Hidrelétrica Baixo Iguaçu com base nas teorias de Young $(2000,2006)$ e Hannigan (1995). O estudo de campo foi levado a efeito com moradores atingidos dos municípios paranaenses de Capitão Leônidas Marques, Capanema, Nova Prata do Iguaçu, Realeza e Planalto. A metodologia utilizada incluiu análise documental e análise de conteúdo de entrevistas semiestruturadas, aplicadas junto aos moradores e às lideranças das organizações que atuam na região. Pode-se concluir que a perspectiva social dos atingidos é construída a partir de sentimentos de ansiedade e insegurança, na medida em que eles percebem desvantagens como prejuízos econômicos, psicológicos e sociais, principalmente, devido ao tempo de espera para a resolução dos conflitos e a conclusão do processo de implantação da hidrelétrica.

Palavras-chave | Moradores atingidos; perspectiva social; Paraná; Usina Hidrelétrica Baixo Iguaçu.

Código JEL | Q48; R52; z18.

\section{THE SOCIAL PERSPECTIVE OF RESIDENTS AFFECTED BY THE HYDROELECTRIC PLANT BAIXO IGUAÇU}

\begin{abstract}
This study objectives to understand the social perspective of the residents affected by hydroelectric Baixo Iguaçu, based on Young's (2000, 2006) and Hannigan (1995) theories. The field study was realized out with residents living in the Parana's municipalities Capitão Leônidas Marques, Capanema, Nova Prata do Iguaçu, Realeza and Planalto. The methodology used was: analisys of documents and semi-structured interviews with residents affected and leaders of the organizations which were active in this process. We can conclude that the social perspective of those affected by the implementation of hydroelectric is constructed from feelings of anxiety and insecurity. They realize disadvantages in the process, such as economic, psychological and social
\end{abstract}


damage, mainly coming from the waiting time for the resolution of conflicts and implantation of the hydroelectric.

Keywords | affected residents; hydroelectric plant Baixo Iguaçu; Paraná; social perspective.

JEL-Code | Q48; R52; Z18.

\section{LA PERSPECTIVA SOCIAL DE HABITANTES AFECTADOS POR LA CENTRAL HIDROELÉCTRICA BAIXO IGUAÇU/PR}

\section{Resumen}

Este trabajo es resultado de un estudio que buscó comprender la perspectiva social de los habitantes afectados por la Hidroeléctrica Baixo Iguaçu, con base en las teorías de Young (2000, 2006) y Hannigan (1995). El estudio de campo fue realizado con residentes afectados de los municipios paranaenses de Capitão Leônidas Marques, Capanema, Nova Prata do Iguaçu, Realeza y Planalto. La metodología utilizada incluyó análisis documental y de contenido de entrevistas semiestructuradas, aplicadas a los moradores y los líderes de las organizaciones que actúan en la región. Se puede concluir que la perspectiva social de los afectados es construida a partir de sentimientos de ansiedad e inseguridad, en la medida que ellos perciben desventajas en el proceso, como pérdidas económicas, psicológicas y sociales, principalmente, debido al tiempo de espera para la resolución de los conflictos y la conclusión del proceso de implantación de la hidroeléctrica.

Palabras-clave | habitantes afectados; perspectiva social; Paraná; Central Hidroeléctrica Baixo Iguaçú.

Código JEL | Q48; R52; Z18.

\section{Introdução}

As fontes energéticas são consideradas um importante gargalo do desenvolvimento do Brasil e do mundo. O "apagão" ocorrido em 2009, que prejudicou a distribuição de eletricidade em dezoito estados brasileiros, forçou a sociedade a refletir sobre como a energia está incorporada no seu dia a dia. Segundo notícias da época (TAVARES, 2009), a queda de energia provocou caos em diversas cidades, como trânsito confuso devido à falta de sinais, fechamento de estabelecimentos comerciais, paralisação de metrôs e trens e arrastões que espalharam o medo nas grandes cidades.

Entretanto, os primeiros sinais dos problemas de abastecimento energético no Brasil revelaram-se ainda em 2001 (HAGE, 2008), o que denunciou a falta de investimentos para a geração e transmissão de energia no país. A energia está por trás do modo de viver da população, proporcionando o crescimento dos setores econômicos e um maior conforto às residências. Porém, a energia é também um dos elementos centrais da crise ambiental, pois os modos de produção de energia são causadores de impactos negativos ao ambiente e à sociedade. 
No Brasil, a política federal é a de continuar a priorizar investimentos no setor de geração de energia por meio da água, mesmo com a existência de alternativas melhor aceitas socialmente, como a geração de energias eólica e solar. Sobre o modelo de geração de energia elétrica do país, o Plano Nacional de Energia - PNE 2030 (BRASIL, 2007), planejamento integrado dos recursos energéticos realizado no âmbito do governo brasileiro, concluiu que mesmo com a provável diversificação da matriz energética, a energia hidrelétrica continuará sendo preponderante. O documento apresenta argumentos como o de que o potencial hidrelétrico é de 260 GW, sendo que apenas $68 \%$ desse potencial foi inventariado. Entretanto, há críticas ao PNE alegando que a sociedade não foi consultada na fase de elaboração do estudo.

Além disso, nos últimos anos tem se observado a retomada dos grandes projetos de infraestrutura, como a transposição do rio São Francisco e as grandes hidrelétricas como a Belo Monte. Zhouri, Laschefski e Pereira (2005) afirmam que essas ações lembram a política do governo militar chamada de integração nacional, contudo, esta retomada atual não pretende incentivar somente o crescimento do mercado interno, busca, também, a integração internacional.

Em meio a esse contexto, destaca-se a Hidrelétrica Baixo Iguaçu, que está sendo implantada no Rio Iguaçu, em áreas do Sudoeste do Paraná, na região de fronteira com a Argentina, abrangendo os municípios de Capanema, Capitão Leônidas Marques, Nova Prata do Iguaçu, Planalto e Realeza. As detentoras da concessão desta hidrelétrica são a Neoenergia (com 70\% do total) e a Companhia Paranaense de Energia - Copel (que detém os outros 30\%), formando, juntas, a Geração Céu Azul S.A. A capacidade instalada será de 350,2 MW, potência capaz de abastecer um milhão de pessoas. O custo estimado da obra é de R $\$ 1,6$ bilhão, a previsão do tempo necessário para a construção era de 44 meses e a área alagada de $13 \mathrm{~km}^{2}$ (SOCIEDADE DA ÁGUA, 2008).

A maioria dos estabelecimentos rurais que será impactada pelo projeto está localizada em Capitão Leônidas Marques, município que abrange toda a margem direita do futuro reservatório. Segundo o Relatório de Impacto Ambiental (RIMA) da Usina Hidrelétrica (UHE) Baixo Iguaçu, elaborado no ano de 2008, ao todo 359 famílias deveriam ser indenizadas, destas, 150 proprietárias de áreas de terra e 209 não proprietárias, como empregados, arrendatários e agregados. Entretanto, este número total de atingidos é questionado pelos moradores, que alegam a necessidade de incluir famílias de agricultores que já estavam na área e outras que vieram para a região depois de 2008, como, por exemplo, filhos que já constituíram suas próprias famílias e vivem na área.

A região Sudoeste do Paraná possui um dos maiores potenciais hidráulicos do estado, o que atrai inúmeros investidores. Assim, muitas famílias já foram atingidas pela implantação de hidrelétricas nesta região e, possivelmente, muitas outras irão enfrentar situações semelhantes; por isto, é fundamental ampliar o conhecimento 
sobre este processo e aperfeiçoar os cuidados com a população envolvida nos projetos.

Com isso, este estudo tem o objetivo de investigar a perspectiva social dos moradores atingidos pela implantação da Hidrelétrica Baixo Iguaçu. Com base nas teorias de Young (2000, 2006) e Hannigan (1995), foi investigado o olhar destes atores envolvidos no processo, buscando preencher uma lacuna nos estudos sobre o tema, que, muitas vezes, não enfocam o morador impactado pela construção de uma hidrelétrica.

\section{Os moradores atingidos pela hidrelétrica: referências, pesquisa e análise}

As posições sociais vão produzir experiências particulares e interpretações específicas dos processos sociais e seus resultados. Por isso, "a ideia de perspectiva social sugere que agentes que estão 'próximos' no campo social têm pontos de vista semelhantes sobre esse campo e sobre o que ocorre em seu âmbito" (YOUNG, 2000, p. 163).

Neste estudo de caso, os agentes foram denominados moradores atingidos. Esta categoria foi construída pelos agentes sociais envolvidos pelo problema da desapropriação ocorrida para viabilizar a implantação de hidrelétricas. É uma categoria que busca a agregação social para fins de organização e luta em defesa dos interesses destes grupos, mas, em termos conceituais, a categoria pode produzir imprecisões, posto que oculta a diversidade social dos envolvidos. Diferentes posições sociais implicam em diferenciadas perspectivas de compreensão e lutas sociais.

Silva e Silva (2011) elucidam o que significa o termo "atingido" para as Ciências Humanas. Atingido é aquele morador que sofre os efeitos da construção e posterior funcionamento das hidrelétricas. Os autores citam dois casos: aqueles que são proprietários das terras e aqueles que trabalhavam nas áreas inundadas ou próximas e que têm suas relações de trabalho modificadas. E enumeram uma série de relações de trabalho finalizadas em virtude das implantações de hidrelétricas como "comerciantes fornecedores de produtos a moradores das áreas antes da inundação, trabalhadores artesãos que se utilizavam dos recursos naturais como matéria-prima para produção de seus produtos, trabalhadores assalariados, enfim, cada área inundada possui especificidades e particularidades quanto aos deslocamentos" (SILVA e SILVA, 2011, p. 398).

Para Vainer (2008), o conceito de atingido se trata muito mais do reconhecimento dos direitos daqueles detentores, ultrapassando a ideia estritamente econômica. Compreende-se que o conceito é uma "categoria social em disputa, a noção de atingido varia no tempo e no espaço, conforme os contextos políticos e culturais e, porque não dizê-lo, em consonância com o desenrolar e desenlace dos conflitos 
opondo diferentes atores sociais" (VAINER, 2008, p. 3). Segundo este autor, a única forma de superar as concepções que se baseiam no direito do empreendedor, e não nos direitos das populações atingidas, é entender a natureza do processo social deflagrado pela implantação da hidrelétrica.

Neste estudo, apesar da compreensão de que o conceito de atingido pode representar uma diversidade maior, foram consideradas apenas as famílias que moram e ou se relacionam cotidianamente com estas áreas. Logo, a maioria dos moradores atingidos entrevistados são agricultores familiares.

Nessa categoria, a família proprietária ou responsável pela gestão do estabelecimento rural será a responsável também pelo trabalho na unidade de produção. Wanderley (1996) explica que esta associação não é apenas um detalhe, "o fato de uma estrutura produtiva associar família-produção-trabalho tem consequências fundamentais para a forma como ela age econômica e socialmente" (WANDERLEY, 1996, p. 2). Para a mesma autora, este caráter familiar se expressa nas práticas sociais e:

[...] não se trata apenas de identificar as formas de obtenção do consumo, por meio do próprio trabalho, mas do reconhecimento da centralidade da unidade de produção para a reprodução da família, através das formas de colaboração dos seus membros no trabalho coletivo - dentro e fora do estabelecimento familiar -, das expectativas quanto ao encaminhamento profissional dos filhos, das regras referentes às uniões matrimoniais, à transmissão sucessória, etc. (WANDERLEY, 2003, p. 46).

Outro fator apontado é a característica da diversificação produtiva e da aplicação do princípio da alternatividade, o que não significa que os agricultores familiares não estejam interessados em investir na sua atividade, explica Wanderley (2003). Vários estudos, citados pela autora, comprovaram que a diversificação da produção para o autoconsumo é um objetivo, entretanto as famílias possuem, além da subsistência, a capacidade de investimento, o que aumenta proporcionalmente a integração da unidade de produção aos mercados.

$\mathrm{Na}$ busca pela diversificação, as famílias podem atuar em atividades agrícolas e não agrícolas dentro e fora do estabelecimento, incluindo até atividades no meio urbano, assim, a pluriatividade é "uma estratégia da família, com a finalidade de diversificando suas atividades fora do estabelecimento - assegurar a reprodução desta e sua permanência como ponto de referência central e de convergência para todos" (WANDERLEY, 2003, p. 52).

Chayanov (1974) explica que a mão de obra é o elemento organizativo de qualquer processo de produção e, no caso da agricultura familiar, a composição e o tamanho da família determina essa força de trabalho. Assim, cada membro da família, 
segundo sua idade e gênero, fica responsável por diferentes fases dos afazeres, variando de acordo com a força de trabalho disponível, a demanda de trabalho, a relação entre consumidor e trabalhador e a aplicação dos princípios da cooperação. Sendo que o estímulo inicial da família trabalhadora é a satisfação das necessidades de consumo de seus membros, objetivando a reprodução social desta.

A escolha do objeto para este estudo considerou o conhecimento oriundo da vivência da primeira autora, que atuou na área da comunicação por cerca de cinco anos, divulgando o processo de implantação de hidrelétricas para comunidades atingidas, trabalho desenvolvido nos estados de Goiás e Paraná, além de considerar a revisão bibliográfica e a pesquisa de campo. Primeiramente, foi realizada uma fase exploratória para conhecer a situação e os moradores atingidos, com o objetivo de adequar os instrumentos de pesquisa e a seleção dos atores a serem entrevistados. Assim, para a pesquisa de campo foram utilizadas entrevistas semiestruturadas e a observação participante. A seleção dos entrevistados seguiu critérios não probabilísticos, levou-se em conta a diversidade de situações entre os proprietários e entre os distintos tipos de não proprietários dos estabelecimentos rurais.

A escolha dos entrevistados foi realizada a partir da relação das famílias atingidas, a qual possuía informações como área do estabelecimento, a comunidade onde este se localiza e a descrição complementar das famílias realizada pela diretoria da Associação dos Atingidos pela Hidrelétrica Baixo Iguaçu (ADAHBI). A partir desta descrição, procurou-se selecionar moradores que representassem diferentes comunidades impactadas, níveis econômicos e sistemas de produção.

No critério econômico, foi considerada a área do estabelecimento e a avaliação empírica da diretoria da ADAHBI. A diversidade dos sistemas de produção constatou a existência de atividades como: bovinocultura de leite, avicultura, bovinocultura de corte e grãos como soja, milho e feijão, etc. Além dos diferentes sistemas produtivos, também, foram inseridas famílias pluriativas, isto é, aquelas que possuem membros atuando em atividades agrícolas e não agrícolas.

No total, foram entrevistadas 25 famílias atingidas, sendo dez de Capitão Leônidas Marques, oito de Capanema, quatro de Realeza, duas de Planalto e uma de Nova Prata do Iguaçu. Destas, 21 famílias entrevistadas são proprietárias do estabelecimento atingido e quatro não o são. Entre aquelas que não são proprietárias, mas moram e trabalham em estabelecimentos atingidos, foram entrevistadas duas famílias de arrendatários e duas de funcionários. E, entre as famílias proprietárias, encontraram-se casos mistos de três proprietárias com arrendamentos e uma proprietária que também atua como funcionária, simultaneamente. Como podemos observar na Figura 1, sobre a estrutura fundiária, $56 \%$ dos entrevistados possui até 40 ha.

\section{Figura 1 - Estrutura fundiária dos estabelecimentos dos atingidos pela UHE Baixo Iguaçu entrevistados}




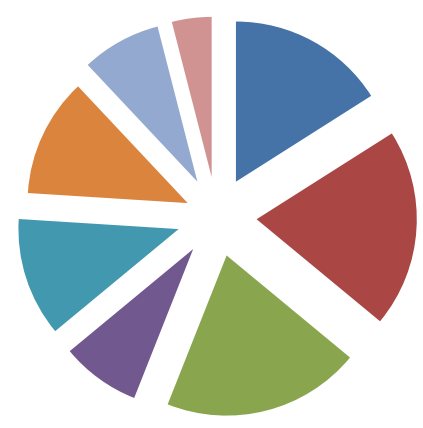

- Não proprietários - $16 \%$

- Até 20 hectares/ Módulo rural PR - 20\%

De 20 ha a 40 ha $-20 \%$

De 40 ha a 60 ha $-8 \%$

De 60 ha a 80 ha $-12 \%$

De 80 ha a 100 ha $-12 \%$

De 110 ha a 130 ha $-8 \%$

450 ha $-4 \%$

Fonte: Pesquisa de Campo, 2013.

Considerando os sistemas de produção dos entrevistados, vinte e duas famílias apresentam pastagem em seu estabelecimento; vinte famílias cultivam milho; quatorze têm eucalipto; treze têm cana-de-açúcar; onze têm soja; doze têm mandioca; oito têm feijão; seis têm trigo; uma tem fumo; uma tem uva e uma tem pinhão manso. A produção de leite merece destaque, pois dezesseis famílias entrevistadas se dedicam à atividade. Na produção animal, vinte famílias criam bovinos de leite e/ou corte; dezoito criam galinhas; dezesseis criam suínos; duas criam peixes; uma família cria patos e outra, cria ovelhas. E ainda, duas famílias se dedicam a atividades de olaria e serraria.

Esse resultado condiz com a característica regional da agricultura familiar, em que a diversificação das atividades na unidade de produção é comum. Algumas famílias produzem para o autoconsumo, com a venda apenas do excedente e outras apresentam uma inserção maior no mercado, com a comercialização de soja, leite, entre outros produtos.

Além das famílias, foram entrevistadas três lideranças das organizações representativas de moradores atingidos: um coordenador do Movimento dos Atingidos por Barragens - MAB, que passou a participar da discussão no segundo semestre de 2013; um assessor da Federação dos Trabalhadores da Agricultura Familiar da Região Sul - FETRAF/SUL, que também faz parte do Comitê da Bacia do Baixo Iguaçu; e o presidente da ADAHBI na época. No relato das falas dos agricultores optou-se por nomes fictícios e nas falas das lideranças foram citadas apenas as instituições que estas representam, como forma de preservar a identidade dos entrevistados.

É necessário acrescentar que o momento vivenciado pelas famílias interfere diretamente nas percepções e opiniões dos entrevistados sobre um processo social, neste sentido, este estudo é delimitado pelo período de tempo compreendido pelo recebimento da Licença de Instalação e o início das negociações com as famílias atingidas. A pesquisa de campo aconteceu em 2013 e a indenização e/ou mudança das famílias ainda não tinha sido concluída em 2017. Em 2013 contatou-se um 
momento já bastante tenso, no sentido das incertezas em relação ao futuro dos moradores, entretanto, logo depois, os conflitos ficaram ainda mais acirrados.

A análise do conteúdo das entrevistas foi realizada a partir das etapas previstas por Bardin (1977). Na etapa do tratamento dos resultados, foram realizadas operações de classificação e comparação das mensagens, para se encontrar as semelhanças e diferenças, analisadas com o amparo das teorias de Young (2000, 2006). Na análise das entrevistas, utiliza-se o conceito de agricultor familiar para melhor caracterizar e compreender o público entrevistado. Este posicionamento dos moradores atingidos na agricultura familiar possibilita uma base mais consistente para a interpretação do conteúdo das entrevistas.

Ao se trabalhar com Young $(2000,2006)$, a pesquisadora sugere que é preciso captar a sensibilidade da experiência do posicionamento em um grupo. Assim, será a partir das percepções individuais que alguns aspectos da realidade vão se sobressair, tornando-se mais visíveis. É também por esse motivo que a perspectiva social não consegue comportar um conteúdo determinado, e, sim, "consiste num conjunto de questões, experiências e pressupostos mediante os quais mais propriamente se iniciam raciocínios do que se extraem conclusões" (YOUNG, 2000, p. 163).

Young (2000) aponta que é possível duas pessoas compartilharem de igual perspectiva social, mas viverem a experiência de seus posicionamentos de maneira diferente. Desta forma:

[...] a perspectiva social é o ponto de vista que os membros de um grupo mantêm sobre os processos sociais em função das posições que neles ocupam. As perspectivas podem ser vivenciadas de um modo mais ou menos autoconsciente. As experiências culturais de povos ou de grupos religiosos diferenciados, bem como de grupos que reagem a uma história de injustiças ou de opressão estrutural, frequentemente lhes conferem interpretações refinadas acerca de suas próprias situações e de suas relações com outros grupos (YOUNG, 2000, p. 164).

Outro autor base da análise de conteúdo desta pesquisa foi Hannigan (1995), que traz a ideia de que um problema só será ambiental quando for social também - o pesquisador destaca a importância de se ouvir os atores sociais. É relevante que as pesquisas "centrem inteiramente na interpretação e práticas dos participantes no problema da construção social" (HANNIGAN, 1995, p. 49), porque para o grande enredo histórico pode ser um problema social, mas para o ator pode ser o contrário. A importância está em questionar: esse fato é um problema social para quem?

A construção de um problema está no mundo do significado, focando no entendimento que os atores têm desses problemas sociais (HANNIGAN, 1995). E, ainda, as preocupações não são constantes, podem variar conforme o tempo. Por 
isso, para entender os problemas sociais de hoje é preciso compreender como os atores sociais percebem estes problemas neste momento.

O exercício da análise desta pesquisa focará na maneira como o problema social da implantação de uma hidrelétrica é construído, conforme as ideias de Hannigan (1995). E, ainda, a forma como o grupo percebe o que acontece - a perspectiva social - conforme as formulações de Young (2000, 2006).

Reconhece-se que o estudo de Hannigan (1995) trabalha com questões ambientais, mas, em seu trabalho o autor não separa o social do ambiental, pelo contrário, enfatiza a necessidade da presença do social na formulação dos problemas, por isso justifica-se sua teoria neste estudo. Também, Young $(2000,2006)$ permite espaço para a perspectiva social que não está nos organismos de política institucionalizados, foco do trabalho desta autora, o que ampara a questão da perspectiva social dos atores envolvidos na temática desta pesquisa.

Além disso, a metodologia utilizada para a compreensão do processo de implantação da hidrelétrica Baixo Iguaçu foi definida a partir dos estudos de Vainer (2008), em que este afirma que a única forma de superar as concepções que se baseiam no direito do empreendedor e perceber os direitos das populações atingidas é entender a natureza do processo social deflagrado pela implantação da hidrelétrica. A partir desta concepção, utilizou-se a noção de impacto social para dar conta da complexidade do objeto e, por meio da perspectiva social, buscou-se o olhar do principal envolvido: o morador atingido. Neste sentido, o entendimento do processo como mudança social implica considerar que há dimensões não estritamente econômicas e materiais, bem como, o reconhecimento da existência de perdas resultantes da desestruturação de relações, da perda de valores, entre outros fatores.

\section{A perspectiva social dos moradores atingidos pela Hidrelétrica Baixo Iguaçu}

Young (2000) trabalha com a ideia de que em sociedades de massa a democracia é descentralizada, acontece por meio da representação e isso não a enfraquece. Entretanto, quando se aborda as normas de representação as queixas são comuns, por muitas vezes serem excludentes. A reclamação é de que os organismos de representação popular não estão devidamente representados nas instituições que tomam decisões políticas ou na mídia. Um exemplo são os ativistas dos movimentos de mulheres, que afirmam que legislaturas majoritariamente masculinas não representam devidamente as mulheres. Tanto é que em diversos países os partidos têm buscado candidaturas femininas, mesmo sem a lei exigir.

A representação é necessária porque é impossível alguém estar ao mesmo tempo em todos os organismos que tomam decisões que podem influenciar suas vidas. Young (2000) foca na representação política, ou seja, candidato e eleitor. Para ela a 
representação oscila entre momentos de autorização e de prestação de contas. Autorização, porque quem representa o grupo precisa estar autorizado a falar em nome deste grupo e a eleição é a forma de autorizar alguém a falar e representar.

O principal problema da representação segundo Young (2000) é a possibilidade de desconexão entre quem representa e o grupo que representa. Levando em conta esse problema a autora conclui que "numa democracia comunicativa inclusiva a representação e a participação não são excludentes, mas requerem uma à outra" (YOUNG, 2000, p. 156). E é justamente por meio da participação ativa que se chega à conexão. Conclui que em sociedades modernas como a atual, a representação passa de necessária a desejável.

Este artigo não está na dimensão da política institucionalizada, como em muitos momentos é o foco da autora, entretanto ela própria ressalta que não são somente nas legislaturas e nos organismos que as teorias de representação de grupos podem ser aplicadas. Também em audiências públicas, comissões, processos consultivos ou organismos que debatem e tomam decisões. Dessa forma, Young (2000) apresenta uma teoria de como a sociedade civil pode contribuir para uma democracia comunicativa e inclusiva. Em que

[...] o processo de autorização e responsabilização que constitui a prática representativa não deve enfim ser confinado aos organismos públicos oficiais. Já assinalei aqui que a livre associação da sociedade civil contribui para a formação e a expressão de interesses e opiniões. A sociedade civil também é uma importante instância de consolidação e expressão de perspectivas sociais (YOUNG, 2000, p. 187).

Cada um será representado por alguns "aspectos da experiência de vida, da identidade, das crenças ou atividades mediante os quais uma pessoa tem afinidade com outras" (YOUNG, 2000, p. 158), o que ocorre no caso das lideranças da ADAHBI e do MAB, entrevistadas nesta pesquisa. Os modos que permitem a alguém ser representado são os interesses, as opiniões e as perspectivas.

Será por meio da perspectiva que os grupos sociais oprimidos conseguirão espaço, porque esta não atribui interesses e opiniões comuns a todos. Young (2000, 2006) exemplifica como alguém se sente representado no processo político: ou será pelos mesmos interesses de quem o representa; ou pelos princípios e valores que norteiam as decisões; e ainda, quando pelo menos alguma deliberação ou discussão expressa uma experiência social igual ao seu seguidor, em razão da posição social semelhante em um grupo.

Sobre os grupos sociais excluídos, a autora lembra que os grupos dominantes ditam as discussões e as decisões políticas, consequentemente, são estes mesmos membros que definem as prioridades políticas. Observar as representações dos grupos minoritários pelo viés da perspectiva social, segundo Young (2000, 2006), é 
considerar que esta perspectiva emerge das estruturas sociais que se posicionam de forma parecida às pessoas daquele contexto, caso elas queiram ou não.

Então, refletir sobre quem são os atingidos por hidrelétricas é ponderar sobre a relevância do lugar para estas famílias. O lugar significa a história de suas famílias, o lar, o seu local de trabalho, a vizinhança, a comunidade, enfim, faz parte da identidade das famílias. Entretanto, é isso que está sendo retirado dos moradores atingidos pela implantação da hidrelétrica, assim, o lugar é a base da construção da perspectiva social destes atores. Para Zhouri e Oliveira (2010, p. 457), "na perspectiva dos chamados 'atingidos' pelos projetos de desenvolvimento, o lugar é referência para a construção de suas identidades políticas, ele significa, sobretudo, a retomada do controle de seu próprio destino".

Zhouri e Laschefski (2010) concluíram que os sujeitos que passam por conflitos, como no caso da ameaça de deslocamento, percebem a necessidade de rever os projetos e as potencialidades das áreas em que vivem. Alguns, inclusive, reconhecem vantagens nas unidades de produção que antes não eram tão visíveis. Muitos afirmaram nas entrevistas estar cientes de que suas áreas são pequenas e por isso têm uma produção limitada, mas, também, sabem que a facilidade de acesso, devido à proximidade da sede do município e da família, tem um valor imensurável.

Como já apontou Hannigan (1995), um problema nunca se materializa por si mesmo. O reconhecimento do problema causado pela necessidade de mudança faz com que as famílias percebam que é preferível e mais seguro permanecer onde estão, pois já conhecem as adversidades relativas ao seu local de moradia e produção e, geralmente, já têm estratégias para contorná-las.

Essa inquietação é maior entre as famílias que estão mais bem informadas sobre o mercado imobiliário da região. Algumas famílias que pesquisaram os estabelecimentos para compra na região manifestaram preocupação com o alto preço das terras e a distância destas em relação ao estabelecimento atual e à sede do município. Em Capitão Leônidas Marques, vários agricultores perceberam a baixa disponibilidade de terras para compra e, por isso, estavam revendo as potencialidades de seus estabelecimentos atuais.

Assim, a investigação da perspectiva social construída pelos moradores atingidos está centrada nas incertezas em relação ao destino de suas famílias: onde vão morar? Conseguirão se manter com a produção na nova área? Quem serão seus vizinhos? Como reconstruirão suas casas? Como seus filhos irão para a escola? Conseguirão reconstruir as benfeitorias? A família conseguirá se adaptar a uma nova comunidade?

E, como estas preocupações não podem ser respondidas pelas organizações que os representam e nem pelos responsáveis pela implantação da hidrelétrica, estas são traduzidas em questões relativas às distintas valorações de sua unidade de produção familiar: o valor da unidade de produção para a família, que é muito mais do que uma simples área de produção; os preços das áreas de terras no mercado regional e 
o valor das indenizações. Estas três noções de valor das terras que serão atingidas pela implantação da hidrelétrica se emaranham constantemente e, no momento analisado, confluem na discussão sobre as indenizações.

A principal questão levantada pelas famílias é a noção de 'indenização justa'. As indagações que aparecem nas falas dos moradores atingidos são: indenização justa para quem? Para o morador que precisará se mudar? Ou conforme o que a empresa quer pagar? A valoração econômica para a indenização das famílias foi problematizada por vários autores, e Pereira e Penido (2010, p. 258) apontam que não são apenas as necessidades básicas dos agricultores que estão ameaçadas e, sim, a questão "subjetiva e simbólica, identitária, afetiva e cultural", entretanto, estas questões são pouco consideradas no processo.

Em sua tese, França (2012) observou a alteração das redes de solidariedade comuns entre os agricultores, nas quais a convivência e as trocas de serviços, equipamentos, produtos e alimentos fazem parte do modo de vida das famílias rurais. A perspectiva de mudança nestas relações já é fonte de ansiedade dos moradores entrevistados. Muitos possuem receio de mudar por não conhecerem os vizinhos, pois, hoje, suas relações são baseadas na confiança construída há muitos anos.

Neste sentido, a primeira dificuldade citada por muitos dos entrevistados é a dificuldade de entrosamento em outro lugar, pois $96 \%$ dos entrevistados residem há mais de 15 anos nas unidades de produção. Sem contar que muitos dos estabelecimentos são heranças de família, e, em alguns deles, chegam a residir três gerações diferentes.

Todos os envolvidos sabem que essas questões precisam ser ponderadas, mas não se observou nenhuma ação proposta pela empresa com esta finalidade no local do estudo, a não ser as audiências públicas realizadas há alguns anos e as reuniões da ADAHBI. E as únicas informações que os moradores possuíam vieram de reuniões da associação de moradores, ou, ainda, de vizinhos que assistiram esses encontros.

Para Pereira e Penido (2010), esse tipo de construção provoca a desterritorialização dos moradores, que resulta na precarização da vida dos atingidos, como foi observado neste estudo de caso. O primeiro morador onde foi instalado o canteiro de obras já tinha sido indenizado na época da aplicação das entrevistas. A família mudou para uma área nova, mas, ainda não tinha plantado sequer um alimento. Considerando que esta família possuía horta e pomar anteriormente e está inserida no contexto da agricultura familiar, que produz grande parte de seus alimentos, este fator é relevante e precariza a segurança alimentar da família. Sem contar que os moradores atingidos possuem ou arrendam pequenas áreas de terra, sem renda fixa e nem sempre contam com reservas que possam supri-los, em caso de necessidade de esperar até a primeira produção na nova área.

As famílias que terão apenas partes de seus estabelecimentos atingidos ficam receosas sobre a possiblidade de não serem indenizadas pela área total destes, porque muitas unidades de produção vão se tornar inviáveis economicamente, por 
se tratarem de áreas pequenas, que se reduzidas, inviabilizam a produção necessária para a manutenção e reprodução da família. Além disso, há incertezas em relação à área a ser atingida pela obra: a falta de marcações no terreno impede que as famílias saibam exatamente qual será a sua perda e alguns moradores não confiam na precisão da área a ser inundada que consta no projeto.

Em relação a isso, em sua entrevista, o morador atingido Farias explica que é contrário ao empreendimento "porque ele liquida com a atividade agrícola da comunidade. É como se dessem um tiro na asa de uma pomba, não deixa a pomba sair porque ela não consegue voar, mas não consegue sobreviver daquele jeito no local" (FARIAS, 2013). O agricultor aponta que, assim como ocorrerá com outras famílias vizinhas, caso fiquem com a metade do estabelecimento a família não conseguirá manter a produção de leite atual, devido à falta de área para o cultivo de pastagens para os animais.

Zhouri e Oliveira (2010) constataram em seu estudo que o setor elétrico construía uma visão que procurava esvaziar a resistência dos moradores e desvalorizar os espaços atingidos. Isto também foi observado neste estudo, quando vários moradores afirmaram discordar da forma com que a empresa pretendia cotar suas unidades de produção. Além disso, os agricultores apontaram que as áreas de pastagens eram consideradas de menor valor pela concessionária, o que não seria correto pelo ponto de vista deles, pois a principal atividade da região é a produção de leite, assim, muitas áreas valorizadas pela localização, topografia e qualidade do solo são destinadas à pastagem.

A empresa e os agricultores apresentam valorações distintas para a mesma área de terra. Os agricultores não consideram apenas os fatores econômicos, mas também, outros elementos que fazem com que sua unidade de produção tenha um valor diferenciado daquele determinado pela empresa. Um dos principais elementos de diferenciação é que a terra faz parte da história da família, forma a identidade do grupo familiar. Isto foi observado quando os moradores faziam uso de suas histórias para justificar a importância daquele local e o porquê eles merecerem ser indenizados justamente. Muitos evocam a quantidade de anos que residem no local, a luta dos pais para adquirir a área e a história de migração até essa região. Zhouri e Oliveira (2010, p. 255) apontam que isso reflete a "ativação da memória coletiva como instrumento de luta na afirmação da legitimidade da ocupação histórica da terra".

Além disso, existem formas variadas de apropriação do espaço natural, dependendo do objetivo determinado pelos agricultores familiares, empresários rurais, produtores de tijolos com a argila da beira do rio, etc. E, com o tempo, as transformações do espaço sofreram interferências agravadas pela demora para a implantação do projeto, pois, muitos proprietários deixaram de investir no estabelecimento devido ao receio de perder o recurso aplicado com a chegada da hidrelétrica. 
Frente à pergunta sobre os sentimentos deles em relação a serem prejudicados pela obra, os entrevistados responderam que se sentem lesados pelos baixos valores oferecidos na indenização e, também, pelo fato de terem ficado estagnados por grande período de tempo, sem investir na unidade de produção devido às incertezas em relação ao futuro. A falta de marcações da área a ser atingida gerou o desconhecimento da área que restaria para a produção da família, fazendo com que eles deixassem de reformar infraestruturas, financiar máquinas e equipamentos, aplicar calcário no solo, o que, consequentemente, diminuiu os ganhos com a produção. Para ilustrar, destaca-se o depoimento de Tomazine:

[...] desde 2004 e até hoje não se sabe ao certo o que vai acontecer com a gente, se eles vão indenizar tudo ou não. A empresa não demonstra esse interesse em indenizar tudo e a gente fica preocupado com isso. Por exemplo, tem gente que tem quatro alqueires e vai atingir dois, o cara vai viver de que forma em cima de dois alqueires? E a empresa não demonstra interesse em indenizar tudo, mas vai ficar inviável (TOMAZINE, 2013).

Assim, outra questão que merece destaque nessa pesquisa está relacionada à espera, pois as companhias não estabelecem prazos e os moradores passam anos esperando por algo que não possuem certeza se vai acontecer. Ao se indagar desde quando os entrevistados sabem que essa usina pode ser construída, cinco afirmaram que ouvem comentários há mais de 50 anos. Outros cinco acreditam que há 15 anos existem boatos sobre a construção da Hidrelétrica Baixo Iguaçu. Ao todo, 76\% dos entrevistados vivenciam a espera pela usina há pelo menos treze anos.

A espera ainda é a realidade desses moradores. Em março de 2017, muitos dos agricultores não tinham sido indenizados e os que receberam tentavam rever os pagamentos para que fossem atualizados conforme os valores de mercado. De 2013 a 2017 foram várias as manifestações e paralisações das obras, inclusive pela via judicial, alegando o descumprimento das condicionantes para a realização da obra, no que diz respeito à garantia dos direitos das pessoas atingidas pelo projeto (GHISI, 2017).

As indefinições e a espera foram resumidas assim pelas famílias: dez famílias afirmaram que esperar pelas obras significa não saber o que fazer (se investe, se não investe, se fica ou se sai), o que os deixa angustiados por não terem nenhuma certeza. Outras oito famílias responderam no sentido de atraso de vida e nos negócios, porque deixaram de investir, o que causou desmotivação em relação ao trabalho. Outras cinco citaram os problemas de saúde ocasionados por essa espera, como nervosismo, depressão e ansiedade. E, ainda, outras cinco famílias citaram a preocupação com a indenização, porque, segundo os entrevistados, com os valores oferecidos não se compra metade da quantidade de área de terra que os mesmos possuem atualmente. 
Nas respostas de três famílias, destaca-se a ideia de aguardar pelo que vai acontecer, como um morador que cita que não regulamentou a documentação das terras por causa da usina e faz 15 anos que ele comprou aquelas terras. Outras duas famílias citaram o medo de ficar sem ter para onde ir.

Duas respostas podem ser encaixadas na categoria das famílias que não modificaram suas rotinas por causa da possibilidade de construção da barragem. É preciso explicar que nessa pergunta existem mais categorias que o número de entrevistados, isso aconteceu porque algumas respostas possuíam duas ideias diferentes. A fim de contabilizar as ideias, elas foram separadas nas diferentes categorias que surgiram ao longo do processo de análise do conteúdo das entrevistas.

Enfim, as preocupações mais comuns se relacionam ao local em que as famílias vão morar. Como o depoimento de Paiva, ao falar que a maior preocupação é "não ter para onde ir, porque se vem a barragem, nós vamos para onde? Você tem sentimento pelo que plantou aqui" (PAIVA, 2013). O depoimento de Silveira explica que "me preocupa bastante o fato deles chegarem e desapropriarem a gente e não termos condições de ter nada, um acerto para nos colocar depois. E se a gente perde esse pedaço da propriedade e não tem para onde ir?" (SILVEIRA, 2013).

O sentimento mais citado é de angústia pelo futuro incerto. Sentimento mencionado pela família Ramos, para o casal esperar pela obra significa:

[...] uma angústia, muita angústia, você fica sem saber o que fazer. Muita gente fala assim - vocês vão perder tudo isso aí. Não vão ganhar nada. Deixam a gente, sabe, pra baixo. A pressão psicológica, tudo isso prejudica bastante. Você trabalhou em cima daquela terra, sofreu, bateu sol em cima de você, agora eles querem te dar 20 mil reais, isso é errado! Não dá para aceitar uma coisa dessas. Quando eu comprei aquilo já paguei um absurdo (RAMOS, 2013).

Também há a preocupação de alguns moradores com os vizinhos e parentes mais velhos, o que se pode perceber no depoimento:

Quando fizeram o levantamento socioeconômico em 2007, naquela época pessoas choravam, casais de 60 a 70 anos choravam porque não sabiam o que iriam fazer. Imagina agora que se passaram todos esses anos, gente que não fez mais investimentos, gente que não sabe mais o que fazer. Por isso eu acho complicado isso aí (TOMAZINE, 2013).

O representante do $\mathrm{MAB}$ também acredita que os moradores já foram prejudicados, antes mesmo do início do empreendimento, pelas incertezas que prejudicam as famílias. 
Do ponto de vista da produção, a sua condição de trabalho, de investimento, perspectiva, isso vai sendo abortado, então eu acho que já existem prejuízos latentes. E mesmo sociais e psicológicos, que são a preocupação, a angústia. Tem relatos de gente que já está em processo avançado de depressão, gente que não consegue mais dormir, está com a ansiedade em fase aguda. Então são várias situações que as próprias famílias relatam que estão vivendo (REPRESENTANTE MAB, 2013).

O representante da FETRAF/SUL cita, como exemplo, o canteiro das obras, "ninguém tinha avisado eles, então tem o prejuízo moral, de desrespeito às famílias, tem uma terra e de certa forma invadem. Vão construir uma usina sem indenizar, sem pagar" (REPRESENTANTE FETRAF/SUL, 2013). Segundo a liderança, a empresa entrou nos estabelecimentos sem avisar, derrubaram cercas, o gado ficou solto e os moradores não sabiam o que estava acontecendo.

Pode-se perceber um sentimento de desamparo e impotência que aparece em diferentes falas dos entrevistados. Tomazine enaltece que "nós temos aqui a prefeitura que nos apoia muito, mas eu acho que nessa área de usina teria que se criar um órgão regulador, para olhar para aquelas pessoas que vão ser atingidas" (TOMAZINE, 2013). O morador explica que na região possuem a experiência da Usina Salto Caxias, segundo ele, existem moradores que foram atingidos uma vez e vão ser atingidos novamente. O morador manifesta o sentimento de desamparo em relação aos órgãos públicos:

Tudo bem, energia o Brasil precisa, mas eu acho que tem que ter um órgão regulador. A ANEEL ${ }^{1}$ dá todos os benefícios para a empresa fazer, pra quem ganha a licitação, mas, e essas terras? Esse povo atingido? Quem está apoiando? Como é organizado? A empresa vai lá e faz o que quer e não tem justiça. A juíza é obrigada a decretar para eles a utilização das terras, mas que lei é essa? Nós não pagamos nossos impostos? Não somos mais donos? Os caras entraram na justiça e a juíza liberou porque existe uma lei dizendo que ela tem que fazer isso, mas onde que estão as condicionantes? Onde vamos buscar apoio? E da Licença Prévia nada se cumpriu. Caso tivessem cumprido estaria ótimo, porque lá nas condicionantes dizia que já tinha que ter feito escola, investido na segurança, a saúde já tinha que ser melhorada. Depois os funcionários vão vir construir e como vão ser atendidos no hospital? Não fizeram nada, o que eles querem é nos tirar e não fazer nada. Você acha que vão fazer depois? Eu acho que precisava existir um órgão regulador para isso. Uma lei, uma proteção às pessoas (TOMAZINE, 2013).

\footnotetext{
${ }^{1}$ ANEEL - Agência Nacional de Energia Elétrica.
} 
O representante do MAB aponta que o modelo atual de geração de energia no Brasil não está para garantir os direitos das populações atingidas e, sim, serve para garantir a implementação do projeto, independente dos impactos ambientais e sociais. "Não têm interesses locais, nem interesses regionais, os interesses são de fora. Essa lógica do desenvolvimento do capital em crise, de buscar as bases vantajosas mais rentáveis, isso que prevalece" (REPRESENTANTE DO MAB, 2013).

Para o líder do MAB, o que está em jogo são os interesses das grandes corporações, a lógica é atender o modelo em que o Brasil exporta matéria-prima, esta é a lógica do desenvolvimento, "tudo que vier de infraestrutura vai ser para atender essas demandas, isso não dialoga absolutamente em nada com o desenvolvimento regional, com o interesse das famílias que vão ser atingidas, com qualquer coisa nesse sentido" (REPRESENTANTE DO MAB, 2013).

Segundo essa liderança, há um padrão de violação de direitos humanos na construção de usinas e isso é intencional, "usa-se estratégias para que não sejam garantidos os direitos, para neutralizar e controlar os anseios, para que as pessoas não se organizem, não busquem garantir aquilo que é de direito delas" (REPRESENTANTE MAB, 2013).

O representante da FETRAF/SUL aponta fontes alternativas de energia, explicando que:

[...] têm outras formas de buscar energia, eu acho que não teria necessidade de fazer mais esse processo de desapropriação de área, no sentido de criar um problema social e o ganho, o lucro dessa geração de energia não ficar no Brasil. São empresas multinacionais, no caso a Copel tem $30 \%$ só, na verdade é um patrimônio que vai fora e a gente não teria mais necessidade de construir usinas aqui, já temos energia sobrando. E o principal não é ter energia sobrando e sim construir outras fontes de energia, essa é a minha posição (REPRESENTANTE FETRAF/SUL, 2013).

As três lideranças entrevistadas manifestaram conhecimento do contexto nacional, esta perspectiva ampla não é percebida nas falas dos moradores entrevistados, que manifestam preocupações mais pessoais e restritas ao momento em que estão vivendo, sem relacionar os problemas específicos de suas indenizações aos processos de outras obras já relatados historicamente. Entretanto, conforme a Comissão Especial chamada 'Atingidos por Barragens' que redigiu um Sumário Executivo, no Conselho de Defesa dos Direitos da Pessoa Humana, o próprio Estado Brasileiro já reconheceu que tem uma dívida histórica com os moradores envolvidos nesse tipo de obra (BRASIL, 2010).

Nesse sentido, a concessionária possui destaque como detentora do poder econômico, por ter sido legitimada pelo Estado, por meio da concessão que autoriza a exploração da água para a geração de eletricidade. Ainda nesse viés, percebeu-se, 
no local, o uso autoritário do Decreto de Utilidade Pública - DUP (BRASIL, 1941). O DUP foi criado pelo Decreto Lei no 3.365, de 21 de junho de 1941, que dispõe sobre as desapropriações de áreas por motivo de utilidade pública. No Artigo $5^{\circ}$ aparecem os casos e na letra (f) são citados os aproveitamentos industriais de águas e de energia hidráulica. Em outros locais, nem sempre esse documento era divulgado e usado para intimidar a resistência dos moradores. Têm-se notícias de obras que conseguiram o DUP em meio à negociação e não antes do processo começar, como foi o caso da Baixo Iguaçu, que teve o DUP publicado em 30 de abril de 2013 (BRASIL, 2016), com parte da documentação necessária. Inclusive Locatelli (2011), em seu estudo na Bacia do Rio Uruguai, citou que o DUP era usado como último recurso, quando toda a negociação e o diálogo já haviam se esgotado.

Outra questão que demonstra a desigualdade de forças foi o não cumprimento de condicionantes das licenças ambientais, sendo que o processo de implantação de hidrelétricas deveria evoluir conforme a concessão das licenças. Iniciaria com a Licença Prévia (LP), na sequência, a Licença de Instalação (LI), e, por último, a Licença de Operação (LO). Estas licenças deveriam resultar na síntese das negociações técnicas e políticas, que seriam feitas antes de sua emissão e, para se conseguir a próxima licença, seria preciso cumprir as condicionantes da licença anterior. Entretanto, não é o que ocorreu no caso estudado.

No processo de implantação da Hidrelétrica Baixo Iguaçu, não se esperou o cumprimento das condicionantes da Licença Prévia, para conceder a Licença de Instalação. Uma das condicionantes que não foi cumprida diz respeito à questão da indenização das áreas atingidas. O documento que deveria ser a síntese das negociações sobre a definição de critérios de reassentamento e desapropriação foi solicitado para conhecimento pela ADAHBI e pelo MAB, mas este não foi apresentado. Entretanto, a Licença Prévia determina a necessidade da apresentação destes critérios ao órgão fiscalizador do Estado - o Instituto Ambiental do Paraná (IAP), no item 19:

Elaborar e apresentar ao IAP documento com a definição dos critérios de reassentamento e desapropriação das propriedades impactadas pelo empreendimento, incluindo as áreas de atividades de extração de areia, basalto, argila e pedreiras impactadas e contendo informações a respeito da condução dos processos de negociações (IAP, 2008).

Essa condicionante é um exemplo de determinação que deveria ser cumprida antes da próxima licença, entretanto, a Licença de Instalação parece ter sido expedida antes mesmo da realização do planejamento sobre os critérios de reassentamento e desapropriação. Descaso que acaba fazendo com que o licenciamento não cumpra o seu papel inicial de nortear os rumos das negociações de forma transparente, pois na fase de aplicação das entrevistas não se tinha acesso a esse documento com os 
critérios de reassentamento e desapropriação, mesmo a desapropriação já tendo iniciado. Procurou-se com os representantes da ADAHBI, MAB, site da empresa e IAP as informações referentes ao cumprimento item 19 da LP, entretanto não se obteve sucesso na busca.

O que Matiello (2011) concluiu em sua tese se repete neste estudo, que os projetos continuam sendo conduzidos de forma autoritária e tecnocrática, pois as licenças simplesmente não são cumpridas e as empresas conseguem outras licenças mesmo sem cumprir condicionantes das licenças anteriores.

Zhouri e Oliveira (2005) já haviam afirmado que os processos de licenciamento perpetuam quadros de injustiças, na medida em que negam a condição dos moradores atingidos como sujeitos. As decisões tomam como base a ideia de que o mercado possui a capacidade de resolver a degradação apenas por meio de compensações ambientais. É o que os mesmos autores chamam de paradigma da adequação ambiental, isto é, propõe superar a crise ambiental sem deixar de lado a modernização e sem mexer no modo capitalista de produção.

Diversos aspectos observados em campo, como o fato dos empreendedores priorizarem a negociação em particular com cada família, dificultando negociações coletivas com a participação das organizações sociais, já haviam sido observados anteriormente em outras pesquisas, como na dissertação de Rossato (2008) sobre a Usina Hidrelétrica Barra Grande, localizado na bacia do rio Uruguai, divisa do estado do Rio Grande do Sul com o de Santa Catarina.

O que se conclui, da cena instaurada no local, é que os principais interessados, moradores atingidos pela implantação, pouco sabem sobre o que vai acontecer, para onde vão mudar, quando esta mudança ocorrerá e quanto receberão de indenização. A empresa além de não divulgar critérios de negociação, para não colocá-los em debate, também evita divulgar informações sobre o andamento do processo e muito menos sobre o cumprimento das condicionantes como, por exemplo, as determinações da Licença Prévia - LP (IAP, 2008), que deveriam nortear todo o andamento do processo.

\section{Considerações finais}

Neste estudo, pode-se concluir que há uma perspectiva social comum entre os moradores atingidos, expressa pela insegurança, pelo receio. Esta é gerada por vários fatores, como: desinformação sobre o processo, a demora, o medo da inviabilização da manutenção e reprodução das famílias, onde vão morar, como comprar outra área, quem serão os seus vizinhos e se todos os moradores atingidos pela implantação da hidrelétrica serão indenizados ou remanejados. E esta perspectiva parte de uma visão bastante negativa do processo e, ainda, resulta em problemas sociais concretos. 
A implantação da Hidrelétrica Baixo Iguaçu já trouxe e pode trazer mais prejuízos econômicos, psicológicos e sociais e os moradores percebem isso. Só o tempo de espera já prejudicou as famílias, através dos efeitos da ansiedade na saúde física e mental dos moradores e das ações que foram deixadas de fazer ou foram feitas devido às possíveis mudanças resultantes da implantação da hidrelétrica, como os investimentos que não foram realizados devido às incertezas sobre o pagamento justo de suas terras e benfeitorias.

Sabe-se que a incerteza perante o futuro é inerente à existência humana, porém, decisões que algumas famílias levam anos planejando, como a construção de uma casa, atormentam os moradores envolvidos pelas incertezas trazidas pelo processo de implantação de uma hidrelétrica. Entre os principais aspectos levantados estão as incertezas em relação à área que será atingida e a falta de marcações no terreno, que deixam dúvidas sobre a permanência ou não das famílias no local. Também, o receio das famílias que devem ter somente metade de suas áreas atingidas e a possibilidade de não serem indenizadas pela área total, pois, muitas das unidades de produção vão se tornar inviáveis economicamente. O desconhecimento da área atingida gerou insegurança nos moradores que acabaram por estagnar a produção, com medo de perder o que teriam investido. Deixaram de reformar infraestruturas, construir casas, financiar máquinas necessárias à produção, tratar com calcário as terras, o que, consequentemente, diminuiu os ganhos com a produção.

A espera das famílias merece destaque na pesquisa, pois várias foram as consequências citadas nas entrevistas, como a angústia pela falta de definições por mais de quatorze anos (muitas famílias relatam tempo maior, mas a configuração atual do projeto é datada em 2004). Neste período, as famílias ribeirinhas passaram por vários estudos, participaram de audiências públicas, dedicaram tempo para saber dos acontecimentos, deixaram de projetar melhorias na infraestrutura porque as terras seriam alagadas, e sofreram com as especulações sobre o andamento ou não do processo.

Outro aspecto que aumenta a angústia das famílias é o fato de que algumas delas não estão computadas nos estudos ambientais. Moradores de duas comunidades dizem possuir problemas de marcação da futura área de alagamento e de preservação permanente. Nos dois casos, os moradores relatam que hoje o rio já sobe mais do que a previsão dos estudos ambientais, principalmente rios e sangas que os ribeirinhos acompanham há anos em épocas de enchentes. O fato de não terem marcado estas terras é visto como problema, pois não permite que os moradores se planejem e, sem saber se poderão ficar na área, é difícil projetar o futuro.

Uma observação que se faz necessária é a existência de algumas diferenças entre os agricultores familiares e os empresários rurais. Uma delas é que os empresários rurais não residem nas áreas atingidas e sim na área urbana, por isso as questões de pertencimento ao local e as relações entre a vizinhança não foram citadas por eles. 
Por outro lado, as relações comunitárias para os agricultores familiares são lembradas como perdas que podem vir a sofrer e como causa de insegurança. Isto acontece pois são entre os vizinhos que eles trocam serviços e alimentos, conseguem crédito quando precisam fazer uma compra e convivem diariamente, baseando estas relações em anos de confiança mútua.

Nas questões relacionadas ao fator psicológico, observa-se nas entrevistas o sentimento de "receio do novo", no sentido de que tudo será diferente e que a adaptação poderá ser difícil. Por outro lado, a maioria dos entrevistados citou planos para a mudança. Aparece, também, o sentimento de desamparo que sentem em relação aos órgãos públicos de modo geral.

O receio da adaptação no novo local - que pode afetar diretamente os rendimentos, pela demora em se adequarem a uma nova área - é uma preocupação levantada principalmente pelos produtores de leite que dependem do pasto e de infraestruturas como a estrebaria e a sala de ordenha. Outros moradores - um possui uma olaria e outro é proprietário de aviários - levantaram a mesma preocupação, porque toda a infraestrutura dos estabelecimentos precisará ser reconstruída.

Ao se abordar questões físicas, características daquela região, destaca-se a escassez de terras que é sentida no local. Isto resulta em preocupações sobre o local em que as famílias vão morar, pois suas infraestruturas serão atingidas e a região carece de áreas disponíveis e com preços compatíveis às indenizações. Outro ponto levantado é a qualidade da terra. Segundo os proprietários, eles perderão o trabalho de anos, tais como as áreas com plantio direto.

Entre as questões econômicas, os valores das indenizações oferecidos pela empresa são considerados muito baixos pelos moradores. Há, ainda, a dificuldade que alguns poderão ter para negociar, devido ao fato de possuírem pouco estudo e, algumas vezes, não saberem negociar.

Em relação à noção de quem é o atingido, os moradores se posicionam no sentido de que todos os que residem no local, proprietários ou não, sejam indenizados ou remanejados para novos estabelecimentos. Entretanto, a empresa não se posicionava sobre a questão, parece que esse não esclarecimento serve de estratégia para limitar a vinda de novos moradores para a área, mas, por outro lado, aumenta a ansiedade de famílias arrendatárias e de trabalhadores.

No breve estudo sobre o modo de produção da agricultura familiar, pode-se concluir que a terra é muito mais que o provento financeiro da família. Ela representa a base estrutural de toda a organização familiar, na qual, por meio da divisão do trabalho se garante a subsistência, a reprodução, a educação dos filhos e a constituição do significado de vida para estas famílias. Por isso, constata-se a necessidade de se ampliar os estudos sob o viés social da perda da terra. 
Também, a preocupação com a segurança alimentar foi percebida e é levantada nas falas dos envolvidos, pois uma das estratégias da agricultura familiar é a produção de alimentos para o autoconsumo, mas a reconstituição de hortas e pomares demandam determinado período de tempo.

Percebem-se algumas diferenças entre a perspectiva social das lideranças com a dos moradores atingidos. Os representantes de movimentos sociais e instituições possuem uma perspectiva ampla, ou seja, conseguem analisar o cenário econômico mundial em que o Brasil está inserido e como a geração de energia e a construção de hidrelétricas ingressam nesse contexto. Essa perspectiva ampla não é percebida nas falas dos moradores entrevistados, que, devido ao momento, apresentam preocupações mais pessoais.

É importante salientar que o processo de implantação da hidrelétrica Baixo Iguaçu ainda está ocorrendo. Foram realizadas reuniões com a participação de mais de 500 moradores atingidos, protestos, invasões do canteiro de obras e reuniões entre a diretoria da ADAHBI e a empresa, com o objetivo de definir claramente os critérios para a indenização e os preços das terras.

Infelizmente, pode-se concluir que pouco mudou no cenário de implantação de hidrelétricas nos últimos anos, pois várias situações levantadas na bibliografia que aborda o tema repetiram-se neste caso. O caminho para possíveis mudanças passa necessariamente pelo reconhecimento dos múltiplos direitos da população atingida, sem contar a importância da continuidade do debate sobre a real necessidade de implantação de hidrelétricas.

Nesse sentido, seria interessante a continuidade do estudo, para acompanhar a mudança nas opiniões e interesses dos moradores atingidos e das lideranças ao longo do processo. Também como o movimento de resistência deu andamento à negociação com a empresa e de que forma conseguiu influenciar as definições da concessionária. Além disso, poder-se-ia investigar todo o processo social de mudança dos moradores atingidos e adaptação nas novas unidades de produção, a percepção de perda e as reconstruções do sentimento de pertencimento ao novo local de moradia. A questão financeira, também, poderia ser tema de trabalho a fim de entender as alterações econômicas das famílias, com os remanejamentos ou indenizações, e quais seriam os critérios mais justos para a indenização.

Algumas ações poderiam diminuir a insegurança dos moradores atingidos perante o processo de implantação de hidrelétricas, como a disponibilização de todos os estudos e planejamentos que envolvem o processo nos sites do IAP e da concessionária. Fato que permitiria a melhor informação dos atores envolvidos no processo e, consequentemente, a diminuição da ansiedade.

Quanto à questão dos licenciamentos, percebeu-se a necessidade de reestruturação das funções dos órgãos ambientais responsáveis que, atualmente, parecem estar licenciando os projetos, independente dos riscos sociais que possam gerar. Talvez, a contratação de funcionários da área social fosse uma alternativa para o melhor 
acompanhamento do processo de indenização e mudança das famílias atingidas. Sem contar que seria necessário um acompanhamento in loco mais intenso dos acontecimentos, pois os relatórios das concessionárias não podem ser considerados fontes confiáveis para a consulta dos processos que dizem respeito aos moradores atingidos.

Apenas a criação de lei específica também não resolveria o problema, seria necessária a normatização dos critérios de indenização, respeitando as diferenças de cada local e o modo de viver de cada população. Esta definiria qual o público a ser indenizado; a fase da implantação em que ocorreria a marcação e a divulgação das áreas a serem atingidas, os critérios e as formas de indenização, entre outros pontos que poderiam deixar a implantação da hidrelétrica mais transparente e diminuiria a ansiedade dos atores envolvidos no processo. Entretanto, a temática é complexa, pois as empresas concessionárias também visam o lucro, por isso buscam por meio das negociações diminuírem os custos.

Este estudo apresentou a perspectiva social construída pelos moradores atingidos frente à implantação de uma hidrelétrica, destacando as inquietações destes e, com isso, a possibilidade de alguns caminhos que poderiam ser possíveis para a diminuição da angústia e dos conflitos provenientes deste processo, como o reconhecimento dos múltiplos direitos da população atingida, a normatização do processo de indenização e de deslocamento dos moradores, bem como a contestação da real necessidade de implantação da hidrelétrica, para assim se pensar em alternativas que se direcionem a um verdadeiro desenvolvimento regional que envolva os sujeitos protagonistas do processo. Sem contar que há a necessidade de construção de um mecanismo com o objetivo de organização e fiscalização do processo que amplie a transparência deste, com a participação dos diferentes grupos de interesse e garantia de espaços de debate e negociação, que possam vir a trazer alternativas pertinentes para a resolução das questões inerentes à implantação das hidrelétricas.

\section{Referências}

BARDIN, Laurence. Análise de conteúdo. Lisboa: Edições 70, 1977.

BRASIL. Declaração de Utilidade Pública, para fins de desapropriação, em favor da empresa Geração Céu Azul S.A. Brasília: Agência Nacional de Energia Elétrica, 2016.

Disponível em: $<$ http://www2.aneel.gov.br/aplicacoes/noticias_area/arquivos/48500.0024942014-66.pdf>. Acesso em: 25 jun. 2017. 
BRASIL. Decreto-Lei No 3.365, de 21 de junho de 1941. Dispõe sobre desapropriações por utilidade pública. Rio de Janeiro, RJ, Diário Oficial, 18 jul. 1941.

BRASIL. Comissão Especial “Atingidos por Barragens" Resoluções n's 26/06, 31/06, 01/07, 02/07, 05/07 Sumário executivo. Brasília: Ministério da Justiça, 2010.

Disponível em <http://portal.mj.gov.br/sedh/cddph/relatorios/sumarioexecutivoaprovadoempl enario_22_11_10.pdf>. Acesso em: 02 mar. 2016.

BRASIL. Plano Nacional de Energia 2030. Brasília: MME e EPE, 2007. Disponível em <http://www.epe.gov.br/PNE/20080512_10.pdf>. Acesso em: 25 jun. 2013.

CHAYANOV, A. V. La organización de la unidad económica campesina. Tradução Instituto de Investigación Científica de Economía Agrícola de Moscú. Buenos Aires: Ediciones Nueva Visión, 1974.

FRANÇA, Georgeana Barbosa de. Crise de energia e governança ambiental: articulações de redes e territórios nas dimensões global e local. Tese (Doutorado em Meio Ambiente e Desenvolvimento) - Universidade Federal do Paraná, Curitiba, 2012.

GHISI, Ednubia. Atingidos pela Usina do Baixo Iguaçu protestam em frente à Neoenergia, em Capanema. Brasil de Fato, Curitiba, 06 mar. 2017. Disponível em: <https://www.brasildefato.com.br/2017/03/06/atingidos-pela-usina-do-baixoiguacu-protestam-em-frente-a-neoenergia-em-capanema/ $>$. Acesso em: 23 jun. 2017.

HAGE, José Alexandre Altahyde. O poder político na energia e relações internacionais: o difícil equilíbrio entre o direito e a busca de segurança do Estado brasileiro. Revista Brasileira de Política Internacional, Brasília, v. 51, n.1, p.169186, $2008 . \quad$ Disponível em: <http://www.scielo.br/scielo.php?script=sci_arttext\&pid=S0034-

$73292008000100009>$ Acesso em: 25 mar. 2018.

HANNIGAN, John A.. Sociologia Ambiental: a formação de uma perspectiva social. Lisboa: Instituto Piaget, 1995.

LOCATELLI, Carlos Augusto. Comunicação e barragens: O poder da comunicação das organizações e da mídia na implantação da Usina Hidrelétrica Foz do Chapecó (Brasil). Tese (Doutorado em Comunicação e Informação) - Universidade Federal do Rio Grande do Sul, Porto Alegre, 2011. 
IAP. N 77034820: Licença Prévia da Usina Hidrelétrica UHE Baixo Iguaçu. Curitiba, 2008.

TAVARES, Mônica et al. Itaipu diz em nota que causa do apagão não teve origem na usina. O Globo, Brasília e Rio de Janeiro, 11 nov. 2009. Disponível em: <https://oglobo.globo.com/economia/itaipu-diz-em-nota-que-causa-do-apagaonao-teve-origem-na-usina-3160242\#ixzz59P962rH9 >. Acesso em: 09 mar. 2018.

MATIELLO, Catiane. Narrativas tecnológicas, desenraizamento e cultura de resistência: história oral de vida de famílias desapropriadas pela construção da usina Hidrelétrica de Itaipu. Dissertação (Mestrado em Tecnologia) Universidade Tecnológica Federal do Paraná, Curitiba, 2011.

PEREIRA, Doralice Barros; PENIDO, Marina de Oliveira. Conflitos em empreendimentos hidrelétricos: possibilidades e impossibilidades do (des)envolvimento social. In: ZHOURI, Andréa; LASCHEFSKI, Klemens (orgs.). Desenvolvimento e conflitos ambientais. Belo Horizonte: Editora UFMG, 2010.

ROSSATO, Alexania. A recepção de rádio e televisão por jovens do Movimento dos Atingidos por barragens: as representações da classe popular. Dissertação (Mestrado em Comunicação) - Universidade Federal de Santa Maria, Santa Maria, 2008.

SILVA, Rene Gonçalves Serafim; SILVA, Vicente de Paulo da. Os atingidos por barragens: reflexões e discussões teóricas e os atingidos do assentamento Olhos D’água em Uberlândia-MG. Sociedade \& Natureza, Uberlândia, n.3, p. 397-408, set/dez. 2011.

SOCIEDADE DA ÁGUA CONSULTORIA AMBIENTAL. UHE Baixo Iguaçu: Relatório de Impacto Ambiental - RIMA. Disponível em <http://www.geracaoceuazul.com.br/Pages/Documentos\%20para\%20Downloa d/eia-rima-2008.aspx>. Acesso em: 10 maio 2017.

VAINER, Carlos. Conceito de "Atingido": uma revisão do debate. In: Franklin Daniel Rothman. (Org.). Vidas Alagadas - conflitos socioambientais, licenciamento e barragens. Viçosa: UFV, 2008.

WANDERLEY, Maria de Nazareth Baudel. Raízes históricas do campesinato brasileiro. XX Encontro Anual da ANPOCS. GT 17. Processos Sociais Agrários. Caxambu: 1996. 
WANDERLEY, Maria de Nazareth Baudel. Agricultura familiar e campesinato: rupturas e continuidade. Revista Estudos Sociedade e Agricultura. no 21. 2003. Disponível $\mathrm{em}$ <http://r1.ufrrj.br/esa/V2/ojs/index.php/esa/article/view/238/234>. Acesso em: 02 jul. 2016.

YOUNG, Iris Marion. Inclusion and democracy. New York: Oxford University Press, 2000.

YOUNG, Iris Marion. Representação política, identidade e minorias. Lua Nova. São Paulo: 2006.

ZHOURI, Andréa; LASCHEFSKI, Klemens. Desenvolvimento e conflitos ambientais. Um novo campo de investigação. In: ZHOURI, Andréa; LASCHEFSKI, Klemens (orgs.). Desenvolvimento e conflitos ambientais. Belo Horizonte: Editora UFMG, 2010.

ZHOURI, Andréa; LASCHEFSKI, Klemens; PEREIRA, Doralice Barros. Desenvolvimento, sustentabilidade e conflitos socioambientais (Introdução). In: ZHOURI, Andréa; LASCHEFSKI, Klemens; PEREIRA, Doralice Barros. A insustentável leveza da política ambiental - desenvolvimento e conflitos socioambientais. Belo Horizonte: Autêntica, 2005.

ZHOURI, Andréa; OLIVEIRA, Raquel. Quando o lugar resiste ao espaço. Colonialidade, modernidade e processos de territorialização. In: ZHOURI, Andréa; LASCHEFSKI, Klemens (orgs.). Desenvolvimento e conflitos ambientais. Belo Horizonte: Editora UFMG, 2010.

ZHOURI, Andréa; OLIVEIRA, Raquel. Paisagens industriais e desterritorialização de populações locais: conflitos socioambientais em projetos hidrelétricos. In: ZHOURI, Andréa; LASCHEFSKI, Klemens; PEREIRA, Doralice Barros. A insustentável leveza da política ambiental - desenvolvimento e conflitos socioambientais. Belo Horizonte: Autêntica, 2005. 
A PERSPECTIVA SOCIAL DE MORAdores ATINGIDOS PELA HidrelÉtrica BaiXo IGUAÇU/PR 
Endereço para correspondência:

Francine Herpich - francine.herpich@gmail.com

Rua Elias Scalco - Luther King

85605400 - Francisco Beltrão, PR, Brasil

Telefone: (46) 999188404

Norma Kiyota-kiyota.norma@gmail.com

BR 158, km 497 - Bom Retiro

85505970 - Pato Branco/PR, Brasil

Telefone: (46) 32131140

84 | Revista Brasileira de Desenvolvimento Regional, Blumenau, 5 (3), P. 57-84, 2017 